\title{
An Anatomy Precourse Predicts Student Performance in a Professional Veterinary Anatomy Curriculum
}

\author{
Margaret A. McNulty ${ }^{1,2 *}$, Michelle D. Lazarus ${ }^{3}$ \\ ${ }^{1}$ Department of Anatomy and Cell Biology, Indiana University School of Medicine, \\ Indianapolis, Indiana \\ ${ }^{2}$ Department of Comparative Biomedical Sciences, Louisiana State University School of \\ Veterinary Medicine, Baton Rouge, Louisiana \\ ${ }^{3}$ Center for Human Anatomy Education, Department of Anatomy and Developmental \\ Biology, Monash University, Melbourne, Victoria, Australia
}

Running Title: Anatomy precourse predicts professional performance

*Correspondence to: Dr. Margaret A. McNulty, Department of Anatomy and Cell Biology, Indiana University School of Medicine, Indianapolis, IN 46202. USA. E-mail : mcnultma@iupui.edu

This is the author's manuscript of the article published in final edited form as:

McNulty, M. A., \& Lazarus, M. D. (2018). An Anatomy Pre-Course Predicts Student Performance in a Professional Veterinary Anatomy Curriculum. Journal of Veterinary Medical Education. https://doi.org/10.3138/jvme.0317-039r 


\section{Abstract}

Little to no correlation has been identified between related previous undergraduate coursework or outcomes on standardized tests and performance in a professional veterinary curriculum, including anatomy coursework. A relatively simplistic method to predict student performance in professional curricula prior to entrance would be advantageous to many. The purpose of this study was to evaluate whether there is a correlation between performance within a previously published veterinary anatomy precourse and subsequent performance within a professional anatomy curriculum. Incoming first year veterinary students in the Louisiana State University School of Veterinary Medicine professional curriculum were asked to participate in a free week-long precourse, prior to semester start, which covered the musculoskeletal anatomy of the canine thoracic limb using dissection-based methods. Student performance, as evaluated by test grades in the precourse, did indeed correlate with test grades in professional veterinary anatomy courses. A significant and positive correlation was identified between precourse final exam performance and performance on examinations in every professional anatomy course. Qualitative analyses of student comments, pertaining to their experience within the precourse, indicated differences in perception of the impact of the precourse between high-, middle-, and low-performing students. These varied perceptions may provide predictive feedback as well as guidance for supporting lower performing students. Together, these results indicate that performance in a weeklong precourse covering only a small portion of canine anatomy is a strong predictor of 
performance within a professional anatomy curriculum. Additionally, the precourse differentially impacts student perceptions of their learning experience.

Keywords: veterinary anatomy education, gross anatomy education, veterinary education, learning outcomes, supplemental instruction, performance predictor 


\section{Introduction}

Prediction of success, both as a student and as a practicing professional, occupies substantial efforts of those within the fields of professional medical education. This process starts with extensive assessment of students' applications, continues as students progress through their professional curricula with assessments and clinical rotation feedback, and endures in residency and in professional careers with the now widely used 360 feedback. Warning signs are evident early in human medical school that may indicate those unfit for the medical career (1-4), however there is a lack of standardization of these warning signs and similar indications have yet to be investigated in veterinary curricula. If a more consistent mechanism for identifying students early were available, support and intervention in these early stages would be more accessible and easily provided and thus be an asset to any admissions office, educator and learner.

Students are initially evaluated for potential success within a professional curriculum during the application process. Often measures relied on in this stage include appraisal of the applicants' prior coursework. Previous research, including work by the co-authors, found minimal, if any, direct correlation between prior undergraduate coursework and performance within a professional veterinary curriculum (5-8). Studies of professional human medical curricula, however, have identified that students with previous classroom experience in anatomy, histology, or other basic science courses are likely to have improved performance within the professional human medical curriculum $(9,10)$. The apparent disconnect between these two professional learning environments may be due to a variety of reasons. In part, these differences may be attributed to the broader application of learned content within these two educational systems. Professional 
veterinary students are required to understand the basic anatomy and physiology of all of the major domestic species (e.g. canine, feline, equine, bovine). This breadth of species comparisons and the associated differences are often not covered in basic anatomy and physiology classes offered at most undergraduate institutions. In contrast, these types of undergraduate courses tend to be more directed towards those pursuing professional human medical education, and therefore primarily focus on human anatomy. Knowledge of the basic anatomy and physiology of one species (e.g. human) may not directly translate into successful knowledge and understanding of differences among multiple species (e.g. domestic quadrupeds). The application process at many veterinary institutions heavily weights performance in prior coursework, particularly in the sciences in the form of upper-level scientific undergraduate coursework (e.g. biochemistry, genetics, anatomy, physiology), and combines this value with performance on standardized exams, specifically the Graduate Record Examinations ${ }^{\circledR}\left(\mathrm{GRE}^{\circledR}\right)$, as indicators of success in veterinary schooling, despite current evidence of the poor predictive status of these markers.

Standardized tests, including the Medical College Admission Test ${ }^{\circledR}$ (MCAT) scores $(9,11)$ and United States Medical Licensing Examination ${ }^{\circledR}$ (USMLE) examinations (4), may be useful to help identify students who are more at-risk for academic difficulty within a professional human medical curriculum, but have not been shown to specifically correlate with performance in a professional curriculum. Nevertheless, professional veterinary students do not have a corresponding MCAT exam prior to application to DVM programs; instead GRE ${ }^{\circledR}$ scores are used. Given that GRE ${ }^{\circledR}$ scores only assess a broad knowledge of verbal reasoning, quantitative reasoning, and 
analytical writing, these scores understandably provide little correlation with students' basic science knowledge that is necessary for success within a DVM curriculum. Professional veterinary students currently also do not participate in a corresponding multi-step medical licensing procedure during their tenure as a professional veterinary student, as occurs for human medical students. Instead, a single licensing exam, the National Board of Veterinary Medical Examiners ${ }^{\circledR}\left(\right.$ NAVLE $\left.^{\circledR}\right)$, is given in their fourth and final year of the curriculum, to assess the knowledge they have accumulated throughout their tenure within the given veterinary program. Thusly, utilizing standardized tests as a method for predicting student performance within a professional veterinary medical curriculum is unadvisable.

In addition to the difficulties with identifying students during the application process who would struggle with the material within a professional curriculum, it remains difficult to identify professional veterinary students already enrolled within the curriculum who may be at risk for failure within the basic sciences courses, including anatomy. Studies utilizing professional human medical student cohorts have identified potential methods to predict students who may need remediation, including within anatomy coursework. Formative assessments in the form of multiple choice quizzes held within a team-based learning medical curriculum have been identified as potential mechanisms in identifying students at risk of failing a human clinical anatomy course (1). Strategies, such as additional exams to replace low scores obtained, have also been developed to provide students at risk of failing anatomy courses an opportunity to improve their grade and as a method of remediation (12). However, best practices for remediation have not been clearly identified, though the inclusion of multiple assessment 
tools to identify at-risk students is warranted (13). An ideal method of identifying students who are struggling with the material would be to encourage students to selfidentify as such. Self-assessment accuracy is important in education as it can result in changes in student behavior, including avoidance of subjects in which they struggle (3). However, poor medical student self-assessment has been demonstrated in anatomy (14) and specifically neuroanatomy (15), and human medical students tend to underestimate their abilities overall (2). The ability of professional veterinary students to self-assess within their education has not been evaluated, thusly, whether this cohort of students would be more or less successful in self-identifying as struggling with the material in an anatomy course and thusly seek help from instructors to result in fewer cases of failure is unclear. Currently, many United States (U.S.) veterinary medical schools do not have a formal method of identifying students who are at risk of failing basic sciences courses throughout their progression within the curriculum, and instead relies upon individual instructors and course directors to monitor students' progress, as well as students themselves to self-identify as struggling within a certain subject.

As outlined above, a large issue with identifying students who may struggle within a professional veterinary medical curriculum is that these students are rarely exposed to courses in their undergraduate education that cover the material they are expected to understand once enrolled in the professional curriculum. Few universities offer upper level science courses specifically directed towards pre-veterinary students that cover anatomy and physiology of the domestic quadrupeds. The extensive differences in anatomical structures and physiological processes among the domestic species is well known, which adds a layer of additional stress and anxiety onto the 
increased amount of material the students are expected to know. Exposure to anatomy prior to beginning a professional curriculum in the form of an anatomy precourse or boot camp has been shown to improve performance within that professional curriculum in both veterinary (8) and human medical (16) settings. The previously established veterinary precourse covers canine musculoskeletal anatomy of the thoracic limb in an abbreviated, truncated timeframe (ten to fifteen hours over one week), using extensive dissection-based learning that closely mirrors what the professional students will experience within the professional anatomy curriculum. This precourse fills a gap in their undergraduate education by providing a platform for direct learning of anatomical structures within at least one of the domestic quadrupedal species, in a laboratory setting identical to their professional experience.

As outlined above, the field of anatomy education is presently lacking in methods to adequately predict student performance within a professional veterinary anatomy curriculum. A one-week anatomy precourse has been developed that is truncated in nature, relatively easy to offer to incoming students, yet still provides students with a framework of knowledge to build upon within the professional anatomy courses (8). This provides an ideal opportunity to test whether this precourse could serve as a method to predict performance within a professional veterinary curriculum. Therefore, the purpose of the current study was to determine whether performance in the abbreviated precourse held at the LSU SVM for incoming first year veterinary students indicated professional anatomy curriculum accomplishments. 


\section{Materials and Methods}

Participant Selection and Study Population

This study was approved by the LSU Institutional Review Board (IRB). Students accepted into the LSU SVM Class of 2019 were emailed during the summer months prior to the start of classes in the fall to identify those who were interested in participating in a week-long anatomy precourse. This precourse was offered free of charge to participants, and covered the musculoskeletal anatomy of the canine thoracic limb. Details and schedule of the precourse have been previously published (8). If students wished to participate, they were asked to respond via email, and slots were assigned on a firstcome, first-serve basis. The overall purpose of the study, to evaluate whether participation in the precourse influenced learning in veterinary anatomy, was conveyed to the students prior to participation. Upon enrollment within the professional curriculum, the Class of 2019 had a mean age 23.3 years (range 20-37), mean of grade point average (GPA) of 3.80 (range 3.26-4.00), and a mean $\mathrm{GRE}^{\circledR}$ score 306 (range 283-330), and included 16 males and 70 females. Out of 88 incoming students, 48 participated in the course in its entirety (55\% participation; 9 males, 39 females).

\section{Students' Previous Anatomical Experience}

Transcripts of incoming students were reviewed to determine the level of prior anatomy courses taken, as previously described (8). In short, classes were ranked according to subject and level based on course titles, and included scores of: 0 (no anatomy course taken), 1 (low level anatomy course), 2 (high level anatomy course), 3 (high level anatomy course geared specifically to domestic quadrupeds), and 4 
(professional veterinary anatomy coursework). Within the Class of 2019, prior anatomy course experience ranged from no prior anatomy coursework (0) to experience within the professional anatomy curriculum (4).

\section{Precourse Description}

A detailed description of the precourse contents and format has been previously published (8). In short, students met three hours per day for five days two weeks prior to the start of the semester. On Day 1, students learned basic terminology and began study of the bones of the canine thoracic limb. Days 2-4 were dedicated to dissection-based learning of the extrinsic and intrinsic muscles of the canine thoracic limb, including origins, insertions, and actions. Prior to dissection, the instructor performed an approximately 20 minute introduction using an overhead camera system (inVisionCam, inVision Inc., Savannah, GA) to demonstrate the structures that would be dissected that day on a prosected dog. Students dissected their own canine cadaver in groups of three students, following an established dissection guide (17) utilized within the LSU SVM professional anatomy curriculum. On Day 5 , students had a one-hour period to review prior to participating in a written and practical examination, covering the material to which they were introduced in the precourse. An overview of the precourse and its relation to the professional curriculum are outlined in Figure 1.

The precourse final examination included both a written and a practical component. The written portion included 10 multiple-choice questions (1 point each) and focused on origins, insertions, and actions of muscles; anatomical relationship of structures; and boney structures. The practical examination was a traditional fill-in-the- 
blank tag-type test including ten questions ( 2 points each, graded in 0.5 point increments); correct spelling was required ( 0.5 point value per question).

\section{Survey and Qualitative Data Collection and Analysis}

All students who participated in the precourse also completed a survey following the completion of the written final examination on Day 5 that included open ended questions regarding their experience in the precourse. These three questions included: (1) In your opinion, what was the best aspect of the course?; (2) What did you take away from this course?; and (3) What would you change about this course?

The comments from each student were collated into a single document, stratified based on students' overall performance, combining both practical and written scores, on the precourse final examination. High performers were defined has having obtained an $80-100 \%$ on the combined test score $(\mathrm{n}=15)$. Middle performers were defined as having obtained a $60-79 \%$ on the combined test score $(n=18)$. Low performers were defined as having obtained $\leq 59 \%$ on the combined test score $(\mathrm{n}=15)$.

A thematic qualitative study as outlined by Sandelowski and Barroso (18) was designed to ask the following question: Did precourse final exam outcomes correlate to students' perceptions regarding the precourse experience? Thematic analysis was undertaken using grounded theory (19-22) to analyze the responses to the questions outlined above. Open coding was undertaken and themes were identified through the process of analysis, not prior to, allowing for the exploration of the impact of student performance in the precourse on their perceived precourse experience. To enhance reliability, open coding and axial coding were done through constant comparative 
methods between the authors of this paper (23). One of the authors (M.D.L.) was not involved in the administration of the precourse, and thusly served as a blinded evaluator. First, themes were identified for all precourse participants. Following this, responses were separated (blindly) by student grades to evaluate whether previously identified themes and subthemes were dependent on eventual student outcome. Of note, students were unaware of their grades when answering the open-ended questions.

\section{Veterinary Anatomy Professional Curriculum and Examinations}

All students enrolled in the LSU SVM professional DVM curriculum participate in three anatomy courses within the first year that start approximately two weeks following the completion of the precourse. The first two courses (VMED1 and VMED2) cover material related to the anatomy of the canine, with feline comparisons, and include basic radiological anatomy. VMED1 focuses mainly on musculoskeletal anatomy excluding the head, and includes nerves and vessels of the neck and cranial thorax. VMED2 covers the anatomy related to the thorax, abdomen, and pelvic regions; nerves and vessels of the thoracic and pelvic limbs; and the entirety of the head. These courses are each three credits, with VMED1 composed of 27 lecture hours and 48 laboratory hours, and VMED2 composed of 24 lecture hours and 42 laboratory hours. Both courses are composed of two examinations, none of which are cumulative in material. The first written test in VMED1 has a total of 180 points, and the second test has a total of 190 points. Both written tests in VMED2 have a total of 170 points. All written examinations are graded in two-point increments. Practical examinations are out of a total of 100 points (0.5 point increments), and correct spelling is required. 
The third course (VMED3, four credits, 24 lecture hours and 72 laboratory hours) teaches the comparative anatomy of the domestic ungulate species (equine, bovine, caprine, porcine), and includes basic radiological anatomy. This course is composed of three examinations where material covered is broken into regions as opposed to systems as in VMED1 and VMED2. The first test covers anatomy of the neck, thorax, and abdomen; the second test covers anatomy of the axial skeleton, pelvis, hindlimb, and hoof; the third test covers anatomy of the forelimb, stay apparatus, and head. Written examinations within this course are out of 120 points total ( 2 point increments). Practical examinations are graded out of a total of 80 points ( 0.5 point increments), and correct spelling is required.

All examinations within these courses are composed of both a written and practical component that are similar, if not identical, in format and composition to the final tests given in the precourse. Grades from the two examinations contained within VMED1 and VMED2, as well as grades from three examinations administered in VMED3, were collected. No students who participated in the precourse were given specialized treatment (e.g. additional or reduced assistance) from professors within the professional curriculum based on their performance in the precourse.

Examinations were not the only assessment used within each of the professional courses. VMED1, VMED2, and VMED3 had additional assessments throughout the course of the anatomy curriculum that were not consistent among each of the three courses. These assessments ranged from in-class quizzes (e.g. identification only), takehome quizzes (to encourage students to complete assigned readings), teamwork scores (to promote collegiality), and credit for participating in class (via audience response 
systems). Given the inconsistent application of these assessments throughout the three professional courses, analysis focused on examination scores only.

\section{Statistics}

Grades from the final examination of the precourse (both written and practical) were compared to grades from each of the examinations in the professional curriculum (written and practical) using Kendall's tau correlation analysis and performed using IBM SPSS v.22. This analysis was chosen for its appropriateness in evaluating non-parametric data (e.g. test scores) and due to the small values contained within the datasets.

\section{Results}

Previous anatomical coursework does not correlate with performance within the professional curriculum

The number of students with no prior coursework in anatomy was evenly distributed between those that took the precourse $(20 / 48,42 \%)$ and those that did not $(14 / 40,35 \%)$. When comparing previous exposure to anatomy via undergraduate coursework (ranked from 0-4 as outlined above under 'Students' Previous Anatomical Experience"), no correlation was found between the level of anatomy course taken and performance in the professional anatomy curriculum, as measured by grade on each examination, within any component of the professional anatomy curriculum (Table 1).

A significant positive correlation found between performance in precourse and professional curriculum 
A significant positive correlation was found between precourse examination grade and examination grades in the professional veterinary anatomy curriculum. The precourse practical examination grades significantly and positively correlated with all seven practical examinations within all three gross anatomy courses (VMED1-3) in the professional veterinary curriculum (Fig. 2, Table 2). Similarly, the precourse written examination grades significantly and positively correlated with five of the seven written examinations within the professional curriculum (Fig. 3, Table 2). The grades from second written examination from VMED2 $(\mathrm{p}=0.188)$ and the second written examination from VMED3 ( $\mathrm{p}=0.116$ ) were the only two tests that did not have a significant positive correlation with the precourse written exam grade. (Table 2)

Qualitative data indicates student perception of the precourse correlate with performance

Identified themes were stratified by grade performance to evaluate the impact that the precourse had on students' differing precourse performance levels. Four themes were identified from students' open-ended responses, prior to stratification: (1) Familiarity with Anatomy Learning Environment; (2) Familiarity with Anatomy Knowledge (3) Skill Acquisition; and (4) Low Pressure Environment. Interestingly, while some themes and subthemes were universal for students of all performance level, some only correlated to middle and/or lower performing students. These themes and subthemes, and how each group of students aligned with each theme, is summarized in a concise table form in Table 3. 
Theme 1: Familiarity with Anatomy Learning Environment

Theme 1 was one of the themes that aligned with all students, regardless of student performance. Subthemes identified within this theme focused on experiences students found relevant in the precourse and included: Dissection Experiences; Preexposure to Course Structure and Learning Environment; Hands-on Experience; and Familiarity with Laboratory Environment. Both high and low performing students identified with Dissection Experiences, with high performing students stating that the "best part of the course" was:

"Getting a chance to actually dissect part of a cadaver before our first anatomy course"

and

"Actually getting to dissect a cadaver."

Similarly, low-performing students reported:

"Pre-exposure to anatomy and dissection."

and

"Having the chance to dissect prior to the start of semester."

All three groups of students identified with Pre-exposure to Course Structure and Learning Environment, where students reported that becoming familiar with the anatomy educational setting was the best part of the course. High Performing students stated:

"Being able to have exposure to the pace of the course in the fall." and "The fact that we get a real look at how the class is going to be structured. Getting our "feet wet" so there are not so many concerns and ambiguity when the real course begins." 
Middle performing students stated:

"I learned what the course will be like, what kind of information will be taught, how I should study, and what to expect."

and

"I took away confidence and a much better awareness of what the course will entail."

Low performing students reported: "gaining experience in a practical setting" and

"Breaking the ice on starting the program. It gives a student some idea of what to expect in the anatomy course, how the class is layed out and what the test look like."

Interestingly, only the middle performing students identified with the last two subthemes: Hands-on Experience and Familiarity with Laboratory Environment.

"The hands-on exposure to gross anatomy."

and

"The hands on approach."

Also stating that the following were the best parts of the course:

"Exposure to how the lab is operated"

and

"gaining experience in a practical setting"

Together these data suggest that familiarity with the learning environment is valuable to all students, but that lower performing students perceive that awareness of the laboratory environment is of particular educational value. 
Theme 2: Familiarity with Anatomy Knowledge

The theme Familiarity with Anatomy Knowledge was only identified in the middle and low performing students, suggesting that knowledge content, as opposed to knowledge context, gained from the anatomy pre-course was more impactful for these students. Subthemes under this theme highlighted the type of learning valued by these students, and feedback was more explicit than the previous theme. Here student comments focused on specific knowledge content and/or understanding they gained from the anatomy precourse and included: Improved General Anatomy Learning, Exposure to Anatomical Language, and Structure Identification. Both the middle and low performing students responded in ways that suggest they appreciated the anatomy precourse because of an overall Improved General Anatomy Learning. With middle performing students stating:

"I gained knowledge about the canine anatomy that will benefit me in the real class." and low performing students commented:

"[I gained] A greater understanding of the dog anatomy." Exposure to Anatomical Language, represented students' reports that the precourse provided opportunities to become familiar with general anatomical terminology. Middle performing students responded that:

"The best aspect of this course was getting exposure to gross anatomy terminology." and 


\section{"Learning the language of anatomy and terminology now rather than in the}

course was the most important aspect to me. That was a block initially."

and low-performing students stated similar benefits of the pre-course highlighting the

following:

"General terms for parts of the anatomy." exposure to "directional terms" and

"anatomical language."

Structure Identification was the other area of specificity identified under Theme 2.

Interestingly, only low performing students identified with this subtheme, stating that the best part of the course was:

"Learning how to look at a dissected animal and find specific structures."

and

"New knowledge on the bones and muscles in a dog"

Together, Theme 2 and encompassing subthemes illustrate a focus on anatomical language and content as being perceived as critical for middle and low performing students. Interestingly, these themes were not identified in high performing students.

\section{Theme 3: Skill Acquisition Theme}

Theme 3, which represented student comments about the abilities they gained from the precourse experience, was represented by student comments from all performance levels. The subthemes under this theme, however, were differentially expressed amongst the student groups. The subtheme of Study Skills was the only Skill acquisition subtheme represented by all students. High performing students stated: 
"I took away some study methods that I feel would be beneficial in this course. I learned how to really use the textbook and also how studying insertions, origins, and actions is important to do at the same time as learning the muscle."

and

"How to prepare!! Didn't realize the importance of learning insertions/origins in tandem with muscles. I need to highlight dissection instructions before lab."

Middle performers responded with:

"I learned what the course will be like, what kind of information will be taught, how I should study, and what to expect."

and

"I now have a good understanding of how to prepare daily for lab and how I will study for each anatomy test."

Similarly, low performers commented:

"The benefits of reading and highlighting the day before class."

and

"How to best study for Anatomy courses."

The other two subthemes under Theme 3 focused on Dissection Skills and Test Taking Skills. Interestingly, these subthemes only aligned with middle and/or low-performing students. For Dissection Skills, both middle and low performers identified with this theme. Middle performers write:

"Knowledge on ... how to wield my instruments properly"

and

"how to correctly dissect the cadaver" 
Low performers commented more on appropriate use of tools. Stating:

"How to use instruments properly."

and

"proper use of tools."

was the best part of the course. Remarkably, only low performers commented on the Test Taking Skills gained in the anatomy precourse, stating:

"Getting a feel for ... testing procedures before school actually starts."

and

"Exposure to...how tests are given."

In summary, this theme reveals that study skills gained in the precourse are perceived as useful for all student levels. Interestingly, dissection and test-taking skills were only discussed by middle and low-performing students.

Theme 4: Low Pressure Environment

The final theme only aligned with middle performing students. The middle performing students stated that the best part of the anatomy precourse was:

"getting an idea of what was expected without pressure."

and

"It was relaxed, short, but still structured well enough to be taken seriously even though there is no true grade."

This qualitative analysis revealed a differential perception of benefits from participation in the precourse, depending on student performance outcome on the 
precourse exam. High performing students focused mainly on gaining course context knowledge and experience while middle and low performing students focused on benefits of gaining content knowledge, in addition to skills, following precourse participation.

\section{Discussion}

An anatomy precourse predicts students' performance within the professional curriculum

Together, our results indicate that participation and performance in a one-week precourse focused in anatomy is a reliable measure of performance within a professional veterinary curriculum. Our results also suggest that participation in an anatomy-focused precourse is an adequate method of identifying students prior to the start of the semester who struggle within the professional anatomy curriculum. The precourse in which the students participated was short (one week, fifteen hours) and covered only a limited amount of material compared to the vast amount covered throughout the first year of the professional curriculum. Despite the extremely truncated format of the precourse, students' performance on the final examination is a very strong indicator of performance within the professional anatomy curriculum. Therefore, this precourse may be a relatively simplistic way to give students a head start and potentially improve their performance within the professional anatomy curriculum. This supports previous work described in the veterinary field (8), but also supports data from other fields. Educational boot camps are widely used in many fields and are gaining popularity, including advanced human medical training $(24,25)$, the basic sciences (26), and undergraduate education (27), though their influence on advanced medical skills has been questioned (28). However, to 
our knowledge, none of these boot camps have correlated student performance in subsequent programs (28).

Our precourse appears to provide instructors and educators with strong data regarding how that student will perform throughout the remainder of the academic year in veterinary anatomy coursework. This type of precourse provides an excellent opportunity for educators to target the poor-performing students early on in the professional curriculum enabling them to use methods to improve struggling students' studying techniques, or assess underlying issues that may negatively affect their grades and performance on other assessments, thereby providing a solution that may result in elimination of the need for remediation completely. To identify whether a subset of students who poorly performed on the pre-course test may have influenced the data, the analyses were re-run excluding the data from the poorest performing students $(n=4)$, and all significant differences as described above remain (data not shown).

While the current study focuses on the correlation between examination assessments in the pre-course compared to each of the professional courses, students were also exposed to a variety of other assessment tools, such as take-home quizzes and participation grades, throughout their tenure within the professional anatomy curriculum. The authors chose not to evaluate a correlation between the pre-course and the other assessments mainly due to their inconsistent presence within the professional veterinary curriculum, and other influencing factors that may not truly reflect a students' learning. One study has identified students who self-reported that they studied far more for a take home test than an in-class test and improved learning of the material as evaluated by subsequent tests (29), however other studies have demonstrated the positive effects of in- 
class tests on retention (30-32). Performance on in-class identification quizzes may be influenced by students' anxiety, as they are aware that they will either receive all points or none for a single question, though the anxiety caused by such in-class testing is debated $(29,33)$. However, despite the other assessments within the professional courses, there were still significant correlations between pre-course test grades and test grades in each professional course.

\section{Familiarity with anatomy course format is related to performance}

One large advantage to the precourse is its format. The structure provides students a dissection-based anatomical learning experience which is mostly self-directed, thus the course mirrors anatomy courses found in professional curricula in the U.S. (34) In addition, undergraduate courses seldom provide in-depth information regarding anatomical structures and other basic biological processes in multiple species, thus these courses provide little preparation for the professional veterinary anatomy curriculum. This can explain why undergraduate coursework rarely correlates with performance within professional veterinary curricula (5-8). This precourse follows a format that closely mimics what the students will experience within their professional anatomy coursework, and thereby gives them an opportunity to determine whether their established study techniques will be applicable and effective in the new learning environment.

In addition, participation in the precourse, or a similar educational boot camp, allows students to become familiar with the teaching methods and their surroundings (8), and have been shown to subsequently increase student confidence (28) and reduce self- 
reported student anxiety (8). Indeed, alleviation of anxiety and stress through familiarity, especially social familiarity, in novel situations is widely accepted $(35,36)$. An increase in familiarity is supported by the qualitative findings within Theme 1, which all students (regardless of precourse performance outcome) perceived as a benefit of the precourse experience. Interestingly, within the student cohort used in the present study, only middle performing students identified with the subthemes Hands-On Environment and Familiarity with Laboratory Environment; both subthemes focus on comments relating to the ability of the precourse to provide students with an opportunity to become familiar with the layout, procedures, and surroundings in the anatomy laboratory. This indicates that middle performing students found the familiarity with the surroundings gained from participation in the precourse to be beneficial to their learning. Interestingly, the lowest performing students were the only learners who perceived value in the dissection experiences and exposure to the course structure. These findings maybe interpreted in two ways. One interpretation is that these students are distracted from what they need or should be focusing on such as familiarity with learning environment and study skill acquisition, as that is where the high achievers focus. In this case support could be provided to these students early on to help refocus these learners on course study techniques and revision strategies. It could also be postulated that high performing students do not perceive a need to focus on this familiarity with the laboratory environment because it is inherent and innate in how they learn as high performers. Work in primary education has shown an influence of novel learning environments on subsequent achievement and attitude levels (37). Further studies will evaluate these potential hypotheses in an effort to enhance precourse achievements and effectiveness. 
Learning strategies influence, or are influenced by, performance

It appears, however, that correlation between precourse grade and grade in the professional anatomy courses begins to weaken by the third course within the professional anatomy curriculum. This could be due to several reasons. First, VMED3 starts five months after the students participated in the precourse. During that time, students have participated in both VMED1 and VMED2, and may have adjusted their study habits in response to their performance within those two courses, and/or secondary to assistance received from anatomy course professors or other educators. Secondly, VMED1 and VMED2 cover carnivore anatomy in detail, as opposed to VMED3, which takes knowledge gained within VMED1 and VMED2 and utilizes it to draw anatomical comparisons between the domestic ungulate species, meaning that structures that are consistent among all species (e.g. extensor carpi radialis m.) are not covered in detail in VMED3, and structures that are different or clinically significant (e.g. gastrointestinal tracts) receive more emphasis in VMED3. Therefore, it could be argued that performance in VMED3 is determined by a students' mastering of deep learning techniques, as opposed to superficial learning via rote memorization; however, the current study does not provide evidence of this theory. It has been identified that utilization of a variety of teaching and assessment methods, such as those used in the professional curriculum of the current study, that incorporate the levels of Bloom's Taxonomy are successfully included in higher education institutions (38). We found that the middle and low performing students in the precourse linked positive feedback for the precourse with lower order learning based on Bloom's Taxonomy. This suggests that students may be 
poor performers because they are valuing the "wrong" lessons of learning (e.g. rote memorization), and that this may be a direct aspect of their learning in which we as educators can intervene and directly address through our teaching methods. Supporting this notion is the qualitative data which shows that only the middle and low performing students aligned with Theme 2, suggesting that content knowledge, as opposed to context knowledge (e.g. familiarity with their surroundings, as outlined above), gained from the precourse was more impactful for these students. Future work will evaluate whether refocusing these lower performing students towards the broader course context and away from the details of course content will help improve their performance in both precourse work and future professional veterinary coursework.

Weaker correlations were identified between the precourse and professional course grades on the written exams when compared to the grades on the practical exams. This is likely due to the material tested within each exam format. Written examinations require students to make connections between the structures (e.g. origin and insertion vs. action of a muscle; relationship of vessels to organs; basic knowledge of neural, cardiovascular, musculoskeletal systems), thereby utilizing studying strategies that result in deeper learning. Practical examinations that are, on the other hand, based mostly upon proper identification of structures on a cadaver and are often associated with superficial learning strategies. It was found that middle and low performing students aligned with the subthemes of Dissection skills and Test taking skills. Similarly to the aforementioned hyper-focus on the laboratory environment, the similar focus on these skills may either be because the students' perceived an inability to adequately master the skills in the 
precourse which is, in turn, causing anxiety for these students, or that the high performing students do not view these skills as critical enough to register in their learning context.

Another perceived benefit to the precourse is that there are no repercussions or benefit to performance on the final examinations. Given that the precourse has no stakes associated with it (the grades given on the final examination do not count for anything), little to no stress is associated with participation. It has been postulated that in order to increase performance in high stakes situations (e.g. the professional curriculum), it may be necessary to encourage students to commit and correct errors in a low-stakes setting (e.g. the pre-course) rather than avoiding errors at all costs (39). Qualitative data indicated that middle performing students were the only cohort who referenced the lowpressure environment of the precourse. This may be because this particular group of students tends to put the most pressure on themselves in an effort to elevate their performance to the level of the high performing students. However, the literature supporting this is inadequate to confirm this theory, and thus future work will focus on identifying the impact of this reduced stress on learning and performance. In addition, the ability of veterinary students to self-assess their performance within a professional curriculum has yet to be examined. Therefore, how the high-, middle-, and lowperforming students are specifically differing in their ability to gauge the effectiveness of their learning strategies within a professional anatomy curriculum, and determine any outside stressors (e.g. anxiety related to the course or curriculum) negatively impacting their performance, is unclear. Qualitative data may be utilized to further enhance the learning experience of poor-performing students within a veterinary anatomy curriculum. 


\section{Limitations}

One of the major limitations of this study is that data from only a single cohort was studied. Future work would gather additional data about similar precourses held at other institutions to indicate whether this format is translatable to other cohorts of students and educators. Another limitation is that the intention of the precourse is to enhance student learning within the professional anatomy curricula, and the authors have previously shown this is true (8). Therefore, it leads one to assume that if the precourse is truly enhancing student learning, the correlations between grades obtained within the precourse and the professional curriculum would be low. What we have previously shown is that the precourse does enhance learning, and while it does so significantly, the overall effect was ultimately less than half a letter grade (5\%) (8). In the current study, a very strong correlation demonstrated between grades in the precourse and professional courses, and this correlation was unlikely to be significantly altered by a score increase of less than 5\%. For example, students who received a 70\% in the precourse may have improved their score to a $75 \%$ in the professional curriculum; conversely students who received a $95 \%$ in the precourse may have improved their score to $100 \%$. However, the mutual relationship between the grades for both students is still maintained. Lastly, students participated in the precourse voluntarily, which may influence the study population. However, similar to the previous study (8), participation in the current study was more than half of the incoming class (55\%), demographics between the two groups was almost identical, and a wide range of performance was also found in the professional curriculum (Figs. $2 \& 3$ ), indicating that volunteers for the precourse weren't limited to 
just the students who thought that they would struggle. Therefore, the theory that these results would be applicable to the entire student population is reasonable.

Overall, we have demonstrated that a simple precourse is a valuable tool in determining students who may perform poorly within a professional veterinary anatomy curriculum. This precourse format may be utilized to identify poor performing students prior to entrance within a professional curriculum. The qualitative data obtained from this study may provide additional insights on how to support lower performing students to elevate their precourse and professional course outcomes. This would allow the opportunity for targeted mentorship by educators to improve learning methods within the low-performing student cohort, and may result in a decrease in failure and/or remediation rates throughout the curriculum. Future work needs to be done to identify if an anatomy precourse is a predictor of student performance in other subjects, such as physiology, and/or whether a similar precourse in other basic science subjects may serve as a similar indicator of student performance. 


\section{Acknowledgements}

The authors would like to thank the anatomy educators at Louisiana State University School of Veterinary Medicine for their assistance in laboratory maintenance and teaching within the professional veterinary curriculum. The authors would also like to thank Dr. Rebecca Christofferson for her statistical assistance. 


\section{Literature Cited}

(1) Azzi AJ, Ramnanan CJ, Smith J, Dionne É, Jalali A. To quiz or not to quiz: Formative tests help detect students at risk of failing the clinical anatomy course. Anat Sci Educ 2015 Sep-Oct;8(5):413-420.

(2) Blanch-Hartigan D. Medical students' self-assessment of performance: Results from three meta-analyses. Patient Educ Couns 2011 Jul;84(1):3-9.

(3) Brown GTL, Andrade HL, Chen F. Accuracy in student self-assessment: Directions and cautions for research. Assess Educ Princ Pol Pract 2015;22:444-457.

(4) Burns ER, Garrett J. Student failures on first-year medical basic science courses and the USMLE step 1: A retrospective study over a 20-year period. Anat Sci Educ 2015 Mar-Apr;8(2):120-125.

(5) Kogan LR, Stewart SM, Schoenfeld-Tacher R, Janke JM. Correlations between preveterinary course requirements and academic performance in the veterinary curriculum: implications for admissions. J Vet Med Educ 2009 Summer;36(2):158-165.

(6) Roush JK, Rush BR, White BJ, Wilkerson MJ. Correlation of pre-veterinary admissions criteria, intra-professional curriculum measures, AVMA-COE professional competency scores, and the NAVLE. J Vet Med Educ 2014 Spring;41(1):19-26.

(7) Rush BR, Sanderson MW, Elmore RG. Pre-matriculation indicators of academic difficulty during veterinary school. J Vet Med Educ 2005 Winter;32(4):517-522.

(8) McNulty MA, Stevens-Sparks C, Taboada J, Daniel A, Lazarus MD. An anatomy precourse enhances student learning in veterinary anatomy. Anat Sci Educ 2016 Jul 8;9(4):344-356.

(9) Huff KL, Fang D. When are students most at risk of encountering academic difficulty? A study of the 1992 matriculants to U.S. medical schools. Acad Med 1999 Apr;74(4):454-460.

(10) Forester JP, McWhorter DL, Cole MS. The relationship between premedical coursework in gross anatomy and histology and medical school performance in gross anatomy and histology. Clin Anat 2002 Mar;15(2):160-164.

(11) Jones RF, Thomae-Forgues M. Validity of the MCAT in predicting performance in the first two years of medical school. J Med Educ 1984 Jun;59(6):455-464.

(12) Daly FJ. Use of electronic anatomy practical examinations for remediating "at risk" students. Anat Sci Educ 2010 Jan-Feb;3(1):46-49. 
(13) Hauer KE, Ciccone A, Henzel TR, Katsufrakis P, Miller SH, Norcross WA, et al. Remediation of the deficiencies of physicians across the continuum from medical school to practice: A thematic review of the literature. Acad Med 2009 Dec;84(12):1822-1832.

(14) Sawdon M, Finn G. The 'unskilled and unaware' effect is linear in a real-world setting. J Anat 2014 Mar;224(3):279-285.

(15) Hall SR, Stephens JR, Seaby EG, Andrade MG, Lowry AF, Parton WJ, et al. Can medical students accurately predict their learning? A study comparing perceived and actual performance in neuroanatomy. Anat Sci Educ 2016 Oct;9(5):488-495.

(16) Herling PJ, Mohseni BT, Hill DC, Chelf S, Rickert JA, Leo JT, et al. Impact of Anatomy Boot Camp on Students in a Medical Gross Anatomy Course. Anat Sci Educ 2017 (in press; doi: 10.1002/ase.1653).

(17) Evans HE, de Lahunta A. Guide to the Dissection of the Dog. 7th Ed. 7th ed. St. Louis, Mo.: Saunders/Elsevier; 2010.

(18) Sandelowski M, Barroso J. Classifying the findings in qualitative studies. Qual Health Res 2003 Sep;13(7):905-923.

(19) Charmaz K. Constructing Grounded Theory: A Practical Guide Through Qualitative Analysis 1st Ed. London, UK: SAGE Publications Ltd.; 2006.

(20) Glaser BG, Strauss AL. The Discovery of Grounded Theory: Strategies for Qualitative Research. 1st Ed. New Brunswick, NJ: Aldine Transactions; 1967.

(21) Saldaña J. The Coding Manual for Qualitative Researchers. 2nd Ed. 2nd ed. Thousand Oaks, CA: SAGE Publications Inc.; 2013.

(22) Whelan A, Leddy JJ, Mindra S, Matthew Hughes JD, El-Bialy S, Ramnanan CJ. Student perceptions of independent versus facilitated small group learning approaches to compressed medical anatomy education. Anat Sci Educ 2015 Jun 3;9:40-51.

(23) Reeves S, Kuper A, Hodges BD. Qualitative research methodologies: Ethnography. BMJ 2008 Aug 7;337:a1020.

(24) Ceresnak SR, Axelrod DM, Sacks LD, Motonaga KS, Johnson ER, Krawczeski CD. Advances in Pediatric Cardiology Boot Camp: Boot Camp Training Promotes Fellowship Readiness and Enables Retention of Knowledge. Pediatr Cardiol 2017 Feb 4.

(25) Schoolfield CS, Samra N, Kim RH, Shi R, Zhang WW, Tan TW. Evaluating the Effectiveness of the General Surgery Intern Boot Camp. Am Surg 2016 Mar;82(3):243250 . 
(26) Shreiber DI, Moghe PV, Roth CM. Multidisciplinary "Boot Camp" Training in Cellular Bioengineering to Accelerate Research Immersion for REU Participants. Adv Eng Educ 2015;4(4).

(27) West RE, Tateishi I, Wright GA, Fonoimoana M. Innovation 101: Promoting Undergraduate Innovation through a Two-Day Boot Camp. Creativity Research Journal 2012;24(2-3):243-251.

(28) Neylan CJ, Nelson EF, Dumon KR, Morris JB, Williams NN, Dempsey DT, et al. Medical School Surgical Boot Camps: A Systematic Review. J Surg Educ 2016 Dec 6.

(29) Marsh R. A Comparison of Take-Home versus In-Class Exams. J Educ Res 1984;78(2):111-113.

(30) Duchastel P. Retention of prose following testing with different types of test. Contemporary Educational Psychology 1981;6:217-226.

(31) Haynie WJ. Effects of pre-tests and post tests on delayed retention learning in technology education. North Carolina Journal of Technology Teacher Education 2004;VI:14-21.

(32) Haynie WJ. Effects of multiple-choice and matching tests on delayed retention learning. Journal of Industrial Teacher Education 2003;40(2):7-22.

(33) Denny JD, Paterson GR, Feldhusen JF. Anxiety and achievement as functions of daily testing. Journal of Educational Measurement 1964;1:143-147.

(34) Choi-Lundberg DL, Low TF, Patman P, Turner P, Sinha SN. Medical student preferences for self-directed study resources in gross anatomy. Anat Sci Educ 2016 MarApr;9(2):150-160.

(35) Terranova ML, Cirulli F, Laviola G. Behavioral and hormonal effects of partner familiarity in periadolescent rat pairs upon novelty exposure. Psychoneuroendocrinology 1999 Aug;24(6):639-656.

(36) Uchino BN, Cacioppo JT, Kiecolt-Glaser JK. The relationship between social support and physiological processes: a review with emphasis on underlying mechanisms and implications for health. Psychol Bull 1996 May;119(3):488-531.

(37) Orion N, Hofstein A. Factors that Influence Learning during a Scientific Field Trip in a Natural Environment. J of Research In Science and Teaching 1994;31(10):10971119.

(38) Choudhury B, Freemont A. Assessment of Anatomical Knowledge: Approaches taken by higher education institutions. Clin Anat 2017 Feb 8. 
(39) Metcalfe J. Learning from Errors. Annu Rev Psychol 2017 Jan 3;68:465-489. 
Figure 1. Timeline of the precourse in relation to the professional veterinary anatomy courses (VMED1-3), and the material covered by each course.

\begin{tabular}{|c|}
\hline Pre-Course \\
5 days; 1 examination \\
Domestic carnivore thoracic limb \\
musculoskeletal system
\end{tabular}




\section{Correlation Between Prior Anatomy Coursework and Each Professional Examination Grade}

\begin{tabular}{|c|c|c|c|c|}
\hline Course & Test & $\begin{array}{c}\text { Test } \\
\text { Component }\end{array}$ & $\begin{array}{c}\text { Correl. } \\
\text { Coef. }\end{array}$ & $\begin{array}{c}\text { P- } \\
\text { Value }\end{array}$ \\
\hline \multirow{4}{*}{ 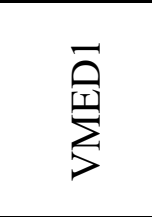 } & \multirow{2}{*}{1} & Written & 0.131 & 0.26 \\
\hline & & Practical & 0.055 & 0.633 \\
\hline & \multirow{2}{*}{2} & Written & 0.153 & 0.185 \\
\hline & & Practical & 0.055 & 0.633 \\
\hline \multirow{4}{*}{ 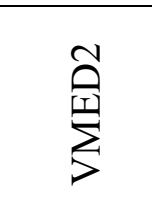 } & \multirow{2}{*}{1} & Written & 0.123 & 0.287 \\
\hline & & Practical & 0.037 & 0.75 \\
\hline & \multirow{2}{*}{2} & Written & 0.027 & 0.819 \\
\hline & & Practical & 0.024 & 0.834 \\
\hline \multirow{6}{*}{$\sum_{>}^{m}$} & \multirow{2}{*}{1} & Written & 0.186 & 0.116 \\
\hline & & Practical & -0.11 & 0.344 \\
\hline & \multirow{2}{*}{2} & Written & 0.108 & 0.363 \\
\hline & & Practical & 0.016 & 0.889 \\
\hline & \multirow{2}{*}{3} & Written & 0.186 & 0.116 \\
\hline & & Practical & -0.11 & 0.344 \\
\hline
\end{tabular}

Table 1. Correlation analyses [as expressed in correlation coefficients (Correl. Coef.)] between ranked previous anatomy coursework and performance on each test within the professional veterinary anatomy curriculum for those students who participated within the precourse. VMED1-3 indicates either the first, second, or third professional anatomy course. 
Correlation Between PreCourse Examination Grades to Each Professional Examination Grade

\begin{tabular}{|c|c|c|r|r|c|r|r|}
\hline Course & Test & $\begin{array}{c}\text { Test } \\
\text { Component }\end{array}$ & $\begin{array}{c}\text { Correl. } \\
\text { Coef. }\end{array}$ & $\begin{array}{c}\text { P- } \\
\text { Value }\end{array}$ & $\begin{array}{c}\text { Test } \\
\text { Component }\end{array}$ & $\begin{array}{c}\text { Correl. } \\
\text { Coef. }\end{array}$ & $\begin{array}{c}\text { P- } \\
\text { Value }\end{array}$ \\
\hline \multirow{2}{*}{ VMED1 } & 1 & Written & 0.288 & 0.01 & Practical & 0.377 & $<0.001$ \\
\cline { 2 - 8 } & 2 & Written & 0.268 & 0.015 & Practical & 0.324 & 0.002 \\
\hline \multirow{2}{*}{ VMED2 } & 1 & Written & 0.263 & 0.017 & Practical & 0.353 & 0.001 \\
\cline { 2 - 8 } & 2 & Written & 0.146 & 0.188 & Practical & 0.306 & 0.003 \\
\hline \multirow{2}{*}{ VMED3 } & 1 & Written & 0.263 & 0.02 & Practical & 0.221 & 0.033 \\
\cline { 2 - 8 } & 2 & Written & 0.178 & 0.116 & Practical & 0.251 & 0.015 \\
\cline { 2 - 8 } & 3 & Written & 0.263 & 0.02 & Practical & 0.221 & 0.033 \\
\hline
\end{tabular}

Table 2. Correlation analyses [as expressed in correlation coefficients (Correl. Coef.)] between student performance on the examination within the precourse and performance on each test within the professional veterinary anatomy curriculum. VMED1-3 indicates either the first, second, or third professional anatomy course. 


\section{Summary of Qualitative Results}

\begin{tabular}{|c|c|c|c|c|c|c|c|c|c|c|c|}
\hline Theme & \multicolumn{4}{|c|}{ Familiarity with Anatomy Learning Environment } & \multicolumn{3}{|c|}{ Familiarity with Anatomy Knowledge } & \multicolumn{3}{|c|}{ Skill Acquisition } & $\begin{array}{c}\text { Low } \\
\text { Pressure } \\
\text { Environment }\end{array}$ \\
\hline $\begin{array}{c}\text { Theme } \\
\text { Summary }\end{array}$ & \multicolumn{4}{|c|}{$\begin{array}{l}\text { Comments which focused on outcomes and impact of } \\
\text { exposure to the course environment (e.g. classroom setup, } \\
\text { grading policy, staff/faculty, schedule) }\end{array}$} & \multicolumn{3}{|c|}{$\begin{array}{l}\text { Comments which focused on impact of } \\
\text { gaining exposure to anatomical content } \\
\text { knowledge }\end{array}$} & \multicolumn{3}{|c|}{$\begin{array}{l}\text { Comments which focused on } \\
\text { gaining skills through } \\
\text { coursework }\end{array}$} & $\begin{array}{c}\text { Comments } \\
\text { that } \\
\text { highlighted } \\
\text { aspects of the } \\
\text { precourse } \\
\text { being low } \\
\text { pressure (e.g. } \\
\text { no grades, } \\
\text { relaxed } \\
\text { environment) }\end{array}$ \\
\hline Subtheme & $\begin{array}{c}\text { Dissection } \\
\text { Experiences }\end{array}$ & $\begin{array}{l}\text { Pre-exposure } \\
\text { to Course } \\
\text { Structure and } \\
\text { Learning } \\
\text { Environment }\end{array}$ & $\begin{array}{l}\text { Hands-on } \\
\text { Experience }\end{array}$ & $\begin{array}{c}\text { Familiarity } \\
\text { with } \\
\text { Laboratory } \\
\text { Environment }\end{array}$ & $\begin{array}{l}\text { Exposure } \\
\text { to } \\
\text { Anatomical } \\
\text { Language }\end{array}$ & $\begin{array}{c}\text { Structure } \\
\text { Identification }\end{array}$ & $\begin{array}{c}\text { Improved } \\
\text { General } \\
\text { Anatomy } \\
\text { Learning }\end{array}$ & $\begin{array}{l}\text { Dissection } \\
\text { Skills }\end{array}$ & $\begin{array}{l}\text { Study } \\
\text { Skills }\end{array}$ & $\begin{array}{l}\text { Test } \\
\text { Taking } \\
\text { Skills }\end{array}$ & N/A \\
\hline & \multicolumn{11}{|c|}{ Alignment of Subtheme with Student Performance in Precourse } \\
\hline $\begin{array}{c}\text { High } \\
\text { Performing }\end{array}$ & + & + & - & - & - & - & - & - & + & - & - \\
\hline $\begin{array}{c}\text { Middle } \\
\text { Performing }\end{array}$ & - & + & + & + & + & - & + & + & + & - & + \\
\hline $\begin{array}{c}\text { Low } \\
\text { Performing }\end{array}$ & + & + & - & - & + & + & + & + & + & + & - \\
\hline
\end{tabular}

Table 3. Summary of qualitative data, including alignment of each subtheme with student cohorts, defined as: high performing (overall precourse grade $\geq 80 \%$ ), middle performing (60-79\%), and low performing $(\leq 59 \%)$. A $(+)$ indicates the subtheme aligned with that student group, a $(-)$ indicates that it did not. 
Figure 2. Scatter plot demonstrating the correlation between student performance on the precourse practical examination and performance on each practical test within the professional veterinary anatomy curriculum. Squares indicate the first test of each course, diamonds indicate the second test of each course, and triangles indicate the third test of each course, if applicable. VMED1-3 indicates either the first, second, or third professional anatomy course.
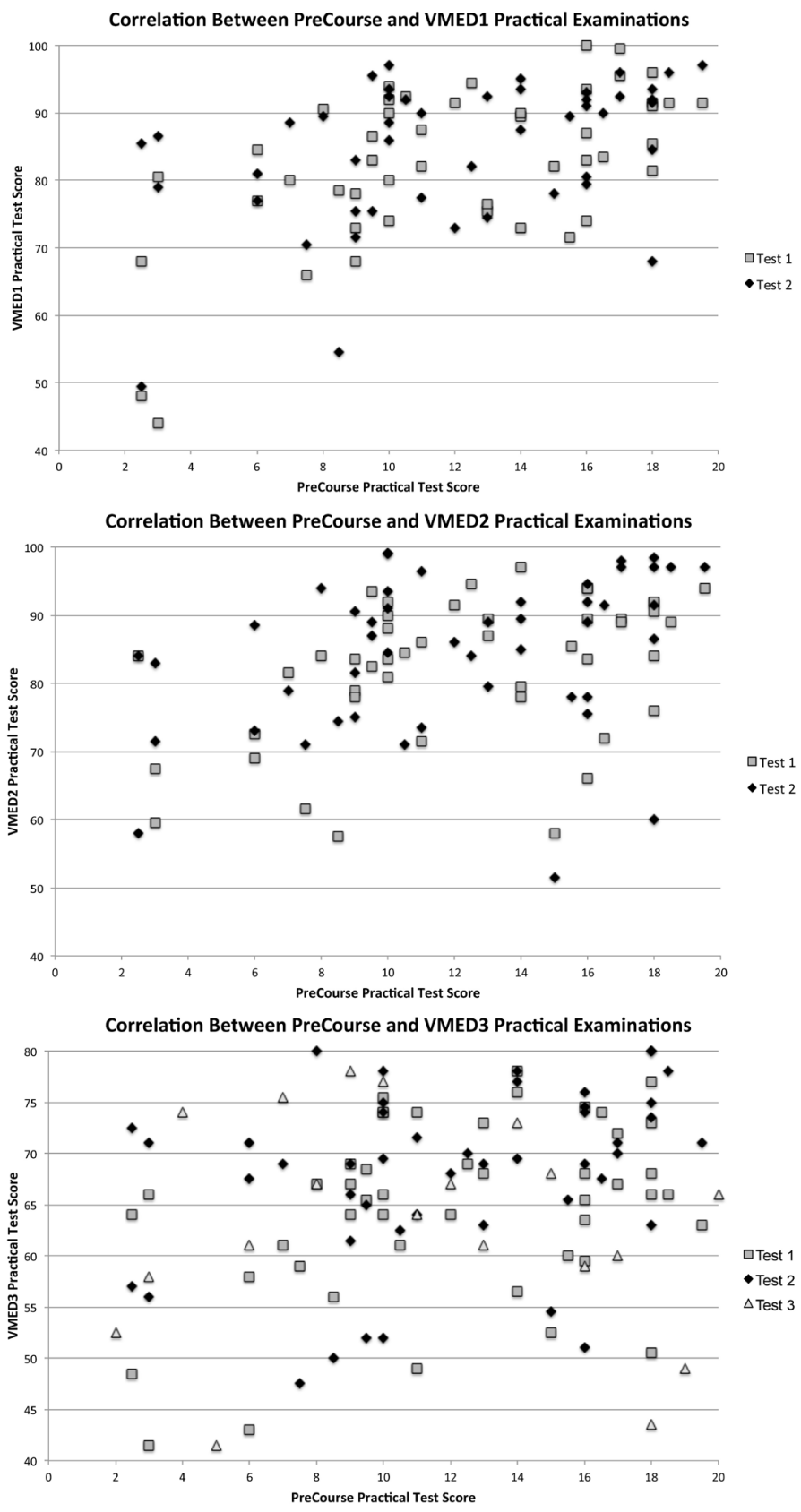
Figure 3. Scatter plot demonstrating the correlation between student performance on the precourse written examination and performance on each written test within the professional veterinary anatomy curriculum. Squares indicate the first test of each course, diamonds indicate the second test of each course, and triangles indicate the third test of each course, if applicable. VMED1-3 indicates either the first, second, or third professional anatomy course.
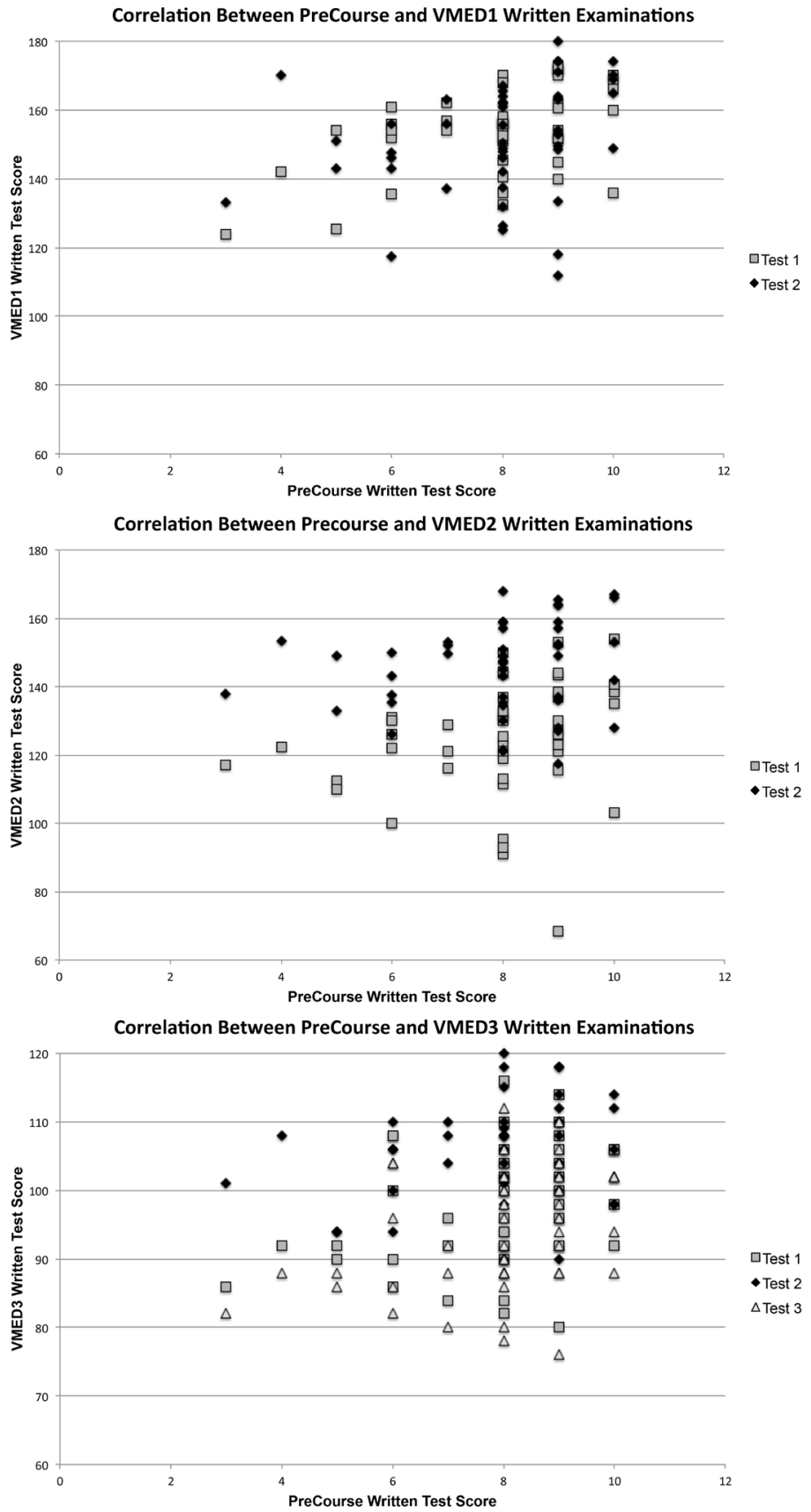